\title{
Developmental Research
}

Kees Klaassen* and Koos Kortland

Freudenthal Institute for Science and Mathematics Education, Utrecht University, Utrecht, The Netherlands

\section{Introduction}

Developmental research is a particular way of addressing the basic questions of why and how to teach what to whom. It involves a cyclical process of small-scale in-depth development and evaluation, at a content-specific level, of exemplary teaching-learning sequences. It aims to produce an empirically supported justification of the inner workings of such a sequence, which is claimed to be an important contribution to the expertise of teachers, curriculum developers, and educational researchers.

\section{The Inner Workings of a Teaching-Learning Sequence}

Two related elements are involved in the intended justification of a teaching-learning sequence about some topic. First, a detailed description of the desired (by the researcher) development in what students believe, intend to achieve, are pleased about, and so on, in relation to the topical contents. Second, a detailed explanation of why students' beliefs, intentions, emotions, etc., can be expected to develop as described, given such and such learning tasks and when guided by the teacher in this and that way. In this explanation the developmental researcher can rely on what may be called commonsense psychology, i.e., what everybody uses all the time to find out about and influence the mental life of others.

Developmental research tries to improve on the practical wisdom of experienced teachers, both in being more detailed and specific with respect to expectations beforehand and in being more systematic and impartial in evaluating whether or not the expectations have come true. Developmental research also aims at more than what can be achieved by a pretest-posttest research design. Such a design may give an indication that a teaching-learning sequence works or fails to work: are the intended learning goals reached, as measured by the progress from pretest to posttest? Developmental research also aims to understand in detail how and why the teaching-learning sequence works or fails to work: does the teaching-learning process itself proceed as hypothesized? It is precisely this detailed content-specific understanding of the process that promises to offer a worthwhile, evidence-based resource to guide professional practice.

\section{Value-Laden Choices}

Separate from the question why a teaching-learning process can be expected to proceed as desired, there is the question of why in the first place it is desirable that there is a teaching-learning process that proceeds in this particular way. Here values necessarily enter the picture. Since the outcomes of developmental research can only be properly communicated and discussed if placed within and

\footnotetext{
*Email: c.w.j.m.klaassen@uu.nl
} 
judged from the value-laden context in which they are obtained, the developmental researcher will at least have to make explicit his value-laden choices. In particular the choices concern the goals he wants pupils to reach and the tenets or principles underlying the ways in which he wants to make pupils reach the goals (such as that students should be actively involved or that they should know all along what they are doing and why). The goals and principles together set the quality standard against which the developmental researcher himself wishes his outcomes to be measured.

From the value-laden character of learning goals and educational principles, it does not follow that they can be chosen freely. The learning goals cannot simply be decided on in advance. Whether they can be realized with sufficient quality, as measured by the developmental researcher's own principles, will have to be investigated. The connection between the educational principles and empirical investigation is much less stringent, and typically the developmental researcher tends to hang on to his principles. But if again and again he fails to meet the quality standard set by his principles, he may eventually begin to question the principles themselves or the theory from which they were derived.

\section{The Heart of Developmental Research}

Whereas commonsense psychology serves to explain why a teaching-learning process can be expected to proceed as desired, there is no theory that serves to actually design the teaching-learning process itself. The developmental researcher will benefit from a deep insight into science, its relations to technology and society, its philosophical foundations and its historical origins, and he may well be inspired by one or another psychological or learning theory. From all of this he may even have derived the goals and educational principles that set the quality standard which the teaching-learning activities he is to generate in the particular case at hand should meet. This standard may function as a checklist, make the developmental researcher receptive to useful ideas, and make him recognize a good idea as such. But the quality standard plays no further facilitating role in actually generating particular teaching-learning activities. The generation of a particular teaching-learning process is an activity sui generis and the very essence of developmental research. In the literature it is variously described as a process in which one's goals and educational principles are applied, implemented, translated, transposed, embodied, given content, or operationalized. But despite all these characterizations, it is a process that refuses to be regularized. Just like any creative process, it is a matter of finding local solutions to local problems. It depends on skill, sweat, talent, persistence, and a good deal of luck. Success or failure may critically depend on details such as the actual wording of tasks.

\section{Vital Methodological Components}

One vital methodological component of developmental research concerns the construction of a so-called scenario or hypothetical teaching-learning trajectory. This consists of the value-laden choices (see section "Value-Laden Choices" above) and the justification of the teaching-learning sequence (see section "The Inner Workings of a Teaching-Learning Sequence"). Simply making explicit the reasons for one's expectations about how the teaching-learning process will proceed may in itself already be sufficient to bring to light quite a lot of wishful thinking. Triangulation in the form of discussing one's scenario with colleagues will make the expectations more realistic by diminishing cases of tunnel vision.

A second vital methodological component is to put the design to the test. This involves the use of the scenario as a theoretical prediction of what will happen. The test then provides the evidence in 
light of which the scenario is to be evaluated. The comparison of the prediction to what actually happens is not straightforward. What actually happens will have to be interpreted in terms of what, at various stages of the process, students believe, mean by what they say, intend to achieve with what they do, and so on. Here too triangulation, in the sense of coordinating the interpretations of various researchers, is a good methodological advice, if only to avert the danger of seeing what one hopes to see (one's predictions). Proceeding in this way, and relying on commonsense psychology, the researcher can make his interpretation as rigorous, systematic, and objective as can be.

A third vital methodological component consists in reflection on the test, in order to improve the scenario in the face of all the points where the expectations did not come out. In some cases it may be possible to "explain away" a deviation. This may happen if the teacher did not guide the activity as intended, while there are indications that students would after all have done what they were expected to do if the activity had been guided as intended. More frequently the deviations reflect a clear need to make adjustments, though typically it will not be so clear which adjustments will suffice. Since a scenario is a highly interrelated complex, a failure that clearly emerges in one area may just be a symptom of a problem elsewhere. Another aspect of the interrelatedness is that necessary changes in one area are likely to require changes in several other areas. Some further, and deeper, complexity may arise if one decides not to make adjustments to the design in order to better realize the process that one wanted, but instead to make adjustments to what one wants the process to be like. That is, one may feel a need to adjust one's educational principles or learning goals.

\section{Nature and Use of Outcomes}

The aim of improving a scenario cannot be to eventually arrive at "the ultimate" scenario - one whose predictions will come out in exactly the predicted way. All that matters is that a scenario can be judged good enough to serve as a valuable guideline for understanding and guiding what goes on in actual classrooms. In each actual case the teaching-learning process will without doubt meander in a somewhat different way around the main predicted path. Several revisions are typically needed before one is even willing to consider the question whether or not a scenario can be judged good enough, and the first revisions are likely to require considerable adjustments. But no matter in how many classes or with how many teachers one has tried a scenario, the claim that it is good enough will always be of the following kind. If handled with proper care, the teaching-learning process will proceed more or less as intended, under normal circumstances. Despite the inherently vague nature of such claims, they are worthwhile, evidence-based contributions to the expertise of teachers, curriculum developers, and educational researchers.

The explicit specification of the value-laden choices and the detailed account of the envisioned teaching-learning process allow a teacher to get a feel of how the process appeals to him. In combination with the empirical support, the teacher can form a judgment as to whether or not he can see it work in his circumstances or see himself able to adapt it to his specific circumstances. In this sense a good enough scenario allows a teacher to reach an informed decision about whether or not to make an effort to use it.

Developmental research aims to engender progress in science education research in at least three ways. First, within the quality standard set by a given matrix of learning goals and educational principles, one good enough scenario may arguably better meet the standard than another one. Second, within the quality standard set by fixed educational principles, for a growing number and variety of topics (with associated learning goals), one may be able to produce good enough scenarios. Third, researchers operating with different quality standards can critically discuss the 
ways in which their respective theoretical perspectives have differently shaped the concrete activities in their respective teaching-learning sequences. At least this may lead to clarification of the educational principles or theoretical perspectives at stake and perhaps even to argumentation about which ones are better. Above all such an exchange will keep theoretical considerations firmly secured to what they are supposed to be relevant for: concrete teaching-learning activities. This is progress too, when compared to the abstract and freewheeling manner in which theoretical frameworks are frequently discussed in the literature.

The developmental researcher does not expect progress in the form of some general body of knowledge by virtue of which curriculum development will be made easier or more efficient. In this respect developmental research may differ from design-based research, in which design principles are often supposed to play such a facilitating or enabling role. It is rather by being exposed to a lot of scenarios, and to empirical tests and critical peer discussions of the scenarios, that curriculum developers are expected to benefit from developmental research.

\section{Drawbacks and Boundaries}

There are important educational issues that typically fall outside the scope of developmental research, such as the following: How can one make the value-laden choices of the developmental researcher a major concern of many teachers? What are useful techniques for teachers to make an envisioned teaching-learning process happen in their classrooms? What about large-scale implementation or dissemination?

Developmental research does not sit easy with the current emphasis on quantity of "output." It takes quite a lot of effort and time to produce a good enough scenario, and because of the formidable complexity of a scenario, it is hard to report concisely its justification and its test. This puts serious pressure on the progress that developmental research aims to engender in what it considers to be the core business of science education research: to construct, critically discuss, and empirically evaluate detailed content-specific justifications of teaching-learning sequences.

\section{Cross-References}

Design-Based Research in Science Education

Educational Reconstruction

Teaching and Learning Sequences

\section{Further Reading}

Barab S, Squire K (eds) (2004) Special issue on design-based research. J Learn Sci 13(1) Gravemeijer KPE (1994) Developing realistic mathematics education. CD $\beta$ Press, Utrecht Kortland K, Klaassen K (eds) (2010) Designing theory-based teaching-learning sequences for science education. CD $\beta$ Press, Utrecht. http://www.staff.science.uu.nl/ kortl101/ book_sympPL.pdf

Méheut M, Psillos D (eds) (2004) Special issue on teaching-learning sequences in connection to the aims and tools for science education research. Int J Sci Educ 26(5) 